\title{
Die roeping van die Gereformeerde Kerke in die Suid-Afrikaanse politiek
}

Dr. Koos Vorster

\section{KERKE EN POLITIEK - DIE DISKUSSIE TOT DUSVER}

Die rol wat die kerk moet speel in die politiek is tans een van die mees besproke temas in die Teologie en ke klike praktyk. Dit is hoofsaaklik die gevolg van die afgelope vier dekades se wêreldwye strewe in die Christendom om Teologie en Kerk meer hedegerig en maatskaplik betrokke te maak. Berkhof $(1967, \mathrm{p} 304)$ het reeds in 1967 hierdie strewe die hooftema van die moderne teologie genoem. Hy het dit gese te midde van die golwinge wat teoloe soos Robinson, Hamilton, Van Buren, Tillich, Altizer en Moltman teweeg gebring het in hulle poging om die Christelike geloof 'n aktuele sosiaalgerigte betekenis te gee. Na hierdie golwinge is die diskussie in detail verder gevoer deur teoloè soos Gutierez, Boff, Bonino, Fierro en ander. Die vrug van al hierdie teologiese besinning het na vore gekom in 'n herorientasie van kerke dwarsoor die wèreld ten opsigte van die sosio-politieke en ekonomiese beplanning van die mens se lewe. Die agendas van ekumeniese byeenkomste, kerklike sinodale vergaderings en die talle verklarings uit kerklike geledere getuig oortuigend van die feit dat kerke tans 'n groot roeping sien in die politiek. Ook in Suid-Afrika het kerke hierdie moderne ontwikkeling intensief beleef (De Gruchy, 1977).

In die formulering en uitlewing van hierdie roeping is daar uiteraard diep verskille. Ideologiese ondertone is sigbaar (Fierro, $1977 \mathrm{p} 182 \mathrm{ev}$ ). Daar is getuienis van kerklike oorgawe aan politieke bewegings (Vorster, 1984 a, p 174 ea). Oor die tema vind daar nuwe verdelings en samevoegings plaas in ekumeniese liggame en kerke. Standpunte wissel op die skaal van "gelowige politiek" aan die een kant en "gepolitiseerde geloof" aan die ander kant. Tussen al die verskille lê daar egter die een saak waaroor Christene vandag nie meer veel verskil nie en dit is dat die kerk 'n roeping het ten opsigte van die politiek van die dag. Die Evangelie raak immers die hele lewe. Die politiek stel die raamwerk waarbinne die moderne lewe plaasvind. Politiek is die aktiwiteit waardeur die lewe van mense deur ' $n$ bepaalde owerheid met wetgewing beoordeel word. In die aktiwiteit moet onderskei word tussen 'n grondliggende filosofiese basis (denke, beleid of ideologie), 'n gevolglike wettesisteem en uiteindelik die implikasies van die toepassing van die sisteem vir mense. Politiek is dus beleid, uitvoering en resultaat. Kerklike handelinge wat enige van hierdie drie elemente aanraak kan dus beskou word as 'n handeling ten opsigte van politiek. Die kerk as 'n gemeenskap wat die Evangelie uitdra kan dus die politiek nie systap nie.

'n Prinsipiële fundering van die roeping van die kerk ten opsigte van die samelewing waarby ingesluit is die politiek, is in gereformeerde kringe voldoende bespreek en hierop word nie hier weer ingegaan nie (Vgl in hierdie verband Floor L, 1974 p 64; Van Wyk JH, 1982 p 28 en Vorster JM. 1984b). 
Die vraag is egter hoe hierdie roeping tans vervul moet word? Hoe moet die kerk hom besig hou met moderne Suid-Afrikaanse politiek sonder om sy eie aard prys te gee of sy profetiese beperkinge te oorskry of om die lakei te word van bepaalde ideologiee. Vir die Gereformeerde Kerke in Suid-Afrika (GKSA) is hierdie vraag tans baie aktueel. Veral omdat gereformeerdes leef binne gemeenskappe waarin totaal botsende ideologieë die uitkyk bepaal. Die vraag is nie maklik om te beantwoord nie. 'n Belangrike stap in die beantwoording van die vraag is om te vra: Hoe het die GKSA die politiek in die verlede gehanteer? Hierop word vervolgens ingegaan.

\section{DIE GKSA EN DIE SUID-AFRIKAANSE POLITIEK IN DIE VERLEDE}

Hoewel daar, soos reeds gesê, vandag besondere nadruk gelē word op die roeping van die kerk ten opsigte van die politiek, was die GKSA lankal reeds op direkte en indirekte wyse betrokke by die Suid-Afrikaanse politiek soos dit hierbo gedefinieer is. Hierdie betrokkenheid kan toegeskryf word aan die roepingsgedagte in die Reformatoriese Teologie. Gestimuleer deur Calvyn, die gereformeerde belydenisskrifte, die kerkbeskouing van Kuyper en die verset teen die wêreldmyding van die Metodisme het die gereformeerdes nog altyd baie gemaak van die roeping van die gelowige en die kerk in die wêreld. Die uitvoering van hierdie roeping het egter konsekwent bestaan uit getuienis van sogenaamde Bybelse beginsels ten opsigte van politieke problematiek en nie die uitbou en propagering van bepaalde stelsels nie. Kerklik kan hierdie getuienis in drie kategorieè verdeel word, naamlik in sinodale verband deur besluitneming, in ekumeniese verband deur identifisering en in plaaslike verband deur die prediking.

\subsection{In sinodale verband}

\subsection{1 'n Kursoriese oorsig van die belangrikste standpunte}

In hierdie opsig moet onderskeidelik verwys word na die vroeëre Generale Sinode, die Nasionale Sinodes in Potchefstroom sedert 1964 en die Algemene Sinode soos hy tans in die Kerkorde art. 29 beskrywe word. Deur hierdie Sinodes is verskeie besluite geneem met direkte implikasies vir die politiek van die dag. Die vroee generale sinodes het besluite geneem teen gemengde huwelike oor die kleurgrense heen (1891, 1920 en 1939) en vir die reg van ' $n$ burger om in sekere omstandighede hom met geweld teen die owerheid te verset. Laasgenoemde besluit is in 1916 geneem na die gespanne tyd van die rebellie wat 'n sterk verdelende faktor order gereformeerdes was. In 1920 is besluit dat vroue nie algemene stemreg mag hê nie en in 1942 teen die bewapening van "nieBlankes" in die weermag (Van Wyk 1983a p 28).

Die meeste besluite ten opsigte van die Suid-Afrikaanse politiek is egter sedert 1957 geneem toe verskeie Nasionale Sinodes in Potchefstroom na studierapporte besluite geneem het oor sogenaamde "Volkereverhoudinge".

Hierdie besluite is in 1985 (Handelinge: $1985 \mathrm{p} 426 \mathrm{ev}$ ) in 'n kronologiese geheel as 'n amptelike dokument van die Nasionale Sinode na oorsese kerke gestuur. Etlike besluite met direkte implikasies vir die Suid-Afri- 


\section{In die Skriflig}

kaanse politiek word hierin aangetref.

So het die Sinode van 1967 die eenheid van die mensheid, die mens as beeld van God en die eis van naasteliefde beklemtoon. In 1970 is die volgende bygevoeg: "Ware liefde tussen mense verg dat ons ons naaste, ongeag sy ras of kultuur, as geskape na die beeld van God aanvaar; dat ons hom as persoon, as skepsel van God, sal respekteer en dat ons gewillig sou wees om ons in sy plek te stel ten einde te begryp hoe ons ons teenoor hom in persoonlike en sosiale verhoudinge behoort te gedra". In die lig van hierdie beginsel word gelowiges opgeroep om die "gebod van liefde in rasseverhoudinge" te verkondig en die kerk moet "houdinge van rassemeerderwaardigheid en vooroordeel uitwis deur sy lede tot volle Christelike volwassenheid in rasseverhoudinge te lei" (GKSA, 1985 p 15). Daarmee saam is besluite geneem by onderskeie sinodes oor die gesinsafbrekende gevolge van trekarbeid; die regte van vreemdelinge en minderhede wat eerbiedig moet word en, waar gebiedskeiding nie moontlik is nie, die verantwoordelikheid van volke en bevolkingsgroepe om onderling in 'n gesindheid van vrede, vryheid, versoening en regverdigheid saam te lewe. Besonder klem word voorts gelê op die beginsels van vrede, geregtigheid, orde, vryheid en versoening as opdrag aan die gelowige in sy verhouding tot ander.

Naas die beginsel van eenheid van die mensheid het sinodes, veral die Sinodes van 1967 en 1985 die realiteit van verskeidenheid beklemtoon met Skrifberoepe soos Hand 2; Hand 3:22; Op $5: 9,7: 9$ ea. Met verskeidenheid as uitgangspunt is verder besluit oor kerklike organisasie en verhoudinge en nie veel oor die politiek nie. Tog is twee besluite van 1970 hier van belang. Die eerste lui: "Elke rassegroep behoort die reg te hê om 'n mate van onderskeie ontwikkeling te verkies, maar nooit ten koste van 'n onderskeidende groep ten opsigte van ras in dieselfde land nie. Terwyl die wyse van sulke ontwikkeling van plek tot plek mag verskil, vereis die Christelike etiek dat liefde en geregtigheid beoefen word en dat alle groepe isolasie vermy en 'n verhouding van onderlinge hulpvaardigheid bevorder." Die tweede lui: "Die beleid van gebiedskeiding sal bevorder word, nie maar omdat dit die beleid van die Owerheid is nie, maar op grond van die belydenis van die gemeenskap van die heiliges en sy roeping tot 'n onbelemmerde uitlewing daarvan. Die profetiese roeping van die kerk sal ook daarin bestaan om die gelowige volk tot 'n kragdadige deurvoering daarvan aan te spoor en alle traagheid hierin te bestraf". Hierdie besluit is egter in 1985 herroep (Handelinge. $1985 \mathrm{p} 444)$ omdat dit die moontlikheid impliseer dat die GKSA 'n bepaalde staatkundige model t.w. "apartheid" ondersteun.

In resente jare het die ander Nasionale Sinodes van die GKSA ook besluite geneem ten opsigte van politiek. Beide Sinodes Middellande en Soutpansberg het ernstige kritiek op die etiese basis, wettesisteem en gevolge van die Suid-Afrikaanse politieke stelsel. Sinode Soutpansberg bepaal: "In a country where capitalism is heralded as an ideology we should show the sin in the system ..." (Nasionale Sinode Soutpansberg 1986 p 3). Skerp kritiek word uitgespreek teen die stelsel van trekarbeid en die magte wat aan ontwikkelingsamptenare toegeken is. Sinode Middellande het fundamentele kritiek teen die "system" en sien dit as 'n kardinale oorsaak van die onrus in Suid-Afkrika. Sinode Suidland het meren- 
deels besig gebly met die kerklike verhoudinge binne die GKSA, maar uit rapporte van die sinode en deputate kan met reg afgelei word dat die "ideologie van apartheid" prinsipieel-krities afgewys word. Deputate van al drie laasgenoemde Sinodes het kritiek uitgespreek teen die Nasionale Sinode (Potchefstroom) se besluite oor Volkereverhoudinge veral ten opsigte van die hantering en toepassing van die realiteit van verskeidenheid en die Skrifberoep hieromtrent.

Die belangrikste besluite van die Algemene Sinode ten opsigte van die Suid-Afrikaanse politiek is in 1980 en 1984 geneem. Die Sinode 1980 (Handelinge, Algemene Sinode van die GKSA, 1980 p 60) het gevolg gegee aan ' $n$ beskrywingspunt van Sinode Suidland met die versoek dat die Sinode vertoe moet rig tot die sentrale regering "om sosiale en ekonomiese omstandighede van die mindergegoede dele van die bevolking te verbeter". Benewens versoeke tot beter onderwys, uitskakeling van sosiale misstande as gevolg van maatskaplike toestande en groter finansiële steun ten opsigte van behuising word die owerheid versoek om: "Onbevrees sorg te dra dat daar 'n staatkundige bedeling sal wees waarbinne elke landsburger sy verantwoordelikhede kan aanvaar as mens wat deur God geskape is en ook sodanige behandeling van ander kan geniet".

Hierop is in 1984 (Handelinge Algemene Sinode van die GKSA 1984, p 46) onder andere gerapporteer dat dit nie hoort: ". . . . tot die taak van die kerk as instituut om hom tot die owerheid te wend met die doel om allerlei staatkundige en maatskaplike veranderinge in die land tot stand te bring nie". Die Sinode het hierdie uitspraak vir sy rekening geneem, hoewel die formulering van die besluit dubbelsinnig is en ook vir ander interpretasies vatbaar is.

\subsubsection{Gevolgtrekkings}

Uit die voorafgaande uiteensetting van standpunte, kan myns insiens die volgende gevolgtrekkings gemaak word:

2.1.2.1 Daar is ooreenstemming binne die GKSA oor die beginsels wat ter sprake is ten opsigte van die politiek. Hieronder word veral klem gelê op die beginsels van eenheid, liefde, geregtigheid en versoening. Daar is verskil oor die belangrikheid van volkereverskeidenheid vir ' $n$ maatskaplike bestel.

2.1.2.2 Die Nasionale Sinodes (Potchefstroom) was versigtig om nie die beleid van apartheid (en latere aanpassings hierop) pertinent te onderskryf nie. Tog gee veral die besluite tussen 1958-1970 blyke van steun by implikasie, van die onderliggende filosofiese basis. Dit is opvallend dat die Sinodes se klem deur die jare verskuif het van verskeidenheid, gebiedskeiding en eiesoortigheid na eenheid, gesamentlikheid en gebiedsdeling.

2.1.2.3 Die Nasionale Sinodes (Potchefstroom) het vir baie jare besig gebly met breë beginsels en, met uitsondering van trekarbeid, art. 16 van die Ontugwet en die wet op Gemengde Huwelike nie die wettesisteem en gevolge daarvan aangespreek nie.

2.1.2.4 Dit blyk dat die ander Nasionale Sinodes in toenemende mate krities staan teenoor die filosofiese basis van die Suid-Afrikaanse stelsel en veral die gevolglike wettesisteem en die implikasies daarvan. Dit moet toegeskryf word aan die feit dat hierdie wette die lewe van swart 


\section{In die Skriflig}

gelowiges intens raak.

\subsection{In ekumeniese verband}

Die GKSA het, vanwee ' $n$ besondere eie siening oor ekumeniese kontak nie verbintenis met die groot internasionale en plaaslike ekumeniese liggame nie. Gevolglik kan met goeie grond beweer word dat die Wêreldraad van Kerke (WRK); die Wèreldbond van Gereformeerde Kerke (WBGK) en die Suid-Afrikaanse Raad van Kerke (SARK) nie noemenswaardige invloed op besluitneming van meerdere vergaderings van die GKSA uitgeoefen het nie. Hierteenoor moet net die teenoorgestelde beweer word van die Gereformeerde Ekumeniese Sinode (GES) waarvan die GKSA 'n stigterslid was.

Baie van die besluite van die Nasionale Sinode (Potchefstroom) is sedert 1958 deur die GES beïnvloed, gestimuleer en selfs in hulle geheel oorgedra. Die belangrikste hiervan is egter die GES se studie oor menseregte wat deur die Nasionale Sinode 1985 aanvaar en onder kerke versprei is (Handelinge GKSA 1985, p 651). Hierdie rapport stel: "Our life is our religion. Therefore, since every societal issue is an intensely human issue, and since every human issue is at heart a religious issue, human rights issues are also deeply religious issues" ( $p$ 629). En verder: "With an undiminished ring of authority the biblical message calls us unceasingly to protect, promote and practice human rights". Gelowiges word gewaarsku teen identifikasie met beide kapitalisme en kommunisme en te strewe na konstitusionele beskerming van menseregte oral en reformasie van instellinge waar hierdie regte ontsē word.

Die rapport gaan verder deur verskeie areas aan te dui waar basiese menseregte deur gelowiges gemanifesteer moet word soos reg om: lewe, basiese behoeftes, gesinslewe, godsdiensvryheid, werk, vryheid van assosiasie, politieke inspraak en verteenwoordiging, keuse van opvoeding, vryheid van diskriminasie, gelykberegtiging en die reg om 'n aandeel in landswelvaart. In hierdie verband word onder andere spesifiek na Suid-Afrika se "legally established discrimination" verwys en die Suid-Afrikaanse kerke, waaronder die GKSA, opgeroep om alles binne hulle vermoe te doen om aan bogenoemde menseregte reg te laat geskied.

Die Nasionale Sinode 1985 het hom met die dokument geidentifiseer en dit beskryf as 'n "waardevolle bydrae vanuit 'n suiwer gereformeerde gesigspunt"' ( $p$ 651). Hierdie besluit is 'n ingrypende besluit wat meebring dat die Sinode homself by implikasie baie krities ingestel het teen die huidige Suid-Afrikaanse stelsel van wetlike diskriminasie. Die besluit het ook verreikende implikasies ten opsigte van vorige standpunte van die GKSA. Die strewe na "gelykberegtiging", "vryheid van assosiasie" en "politieke inspraak" bring mee dat die Sinodes hulle moet uitspreek oor moontlike ander staatkundige modelle. Hiermee het die Sinode dus 'n ander gesigspunt na vore gebring wat in kontras is met die vae standpunt van die Algemene Sinode 1984.

\subsection{In plaaslike verband}

In die gereformeerde kerkregering word baie klem gelè op die prediking in die plaaslike kefk as die eintlike "stem van die kerk". Om vas te stel 
wat die rol van die GKSA was ten opsigte van die Suid-Afrikaanse politiek moet dus ook na die prediking in die plaaslike kerk verwys word. Om hiervan ' $n$ geheelbeeld te kry is moeilik om vas te stel en vereis 'n baie uitvoerige studie. Die taak word bemoeilik deur die gebrek aan navorsingsmateriaal. Wat beskikbaar is, is preekbundels en 'n dieptesnit hieruit bring interessante verskynsels aan die lig.

Dit is opvallend dat Afrikaanse gereformeerde predikante in die eerste plek sterk klem lê op die heilsdade van God en in 'n mindere mate op die heiliging van die lewe as die dankbare reaksie op die verlossende genade in Christus. Die prediking is merendeels leerstellig van aard. Hierdie tendens kenmerk veral die preekbundels in die vorige eeu en eorste dekades van hierdie eeu. Daarna het die toepassing meer verskuif na maatskaplike problematiek soos dobbelary, dronkenskap, materialisme, huweliks- en gesinsverbrokkeling en algemene lewensheiliging. In hierdie verband word die Owerheid vir sy aandeel in maatskaplike sekularisme gekritiseer. In sommige preke is daar 'n duidelike volksgerigtheid dit wil sê, 'n toepassing op die kulturele en politieke milieu van die Afrikaner hoewel dit nie as 'n deurlopende tendens beskryf kan word nie. In 'n preek (Aucamp ea Uit die Iigbron deel 1 sj. p 39) sê J. V. Coetzee byvoorbeeld na aanleiding van Nehemia se leierskap die volgende: "Ag. ons eie volk kan uit droewe ondervinding spreek van sy seuns en dogters wat hulleself van hulle eie volk afgekeer het en hulleself uit hulle volksbodem ontwortel het. Manne en vroue wat in die wêreld opgang gemaak het, maar vir die Boerevolk en sy kultuur en ideale verlore is". Meer sulke volksgerigte preektoepassing op politieke vlak word gevind, veral in ouere preke (Sien ook Van der Walt, 1977 p 14).

Daar kan dus ' $n$ besliste simpatie en identifisering met die politieke stryd van die Afrikaner, in vroeëre preekbundels waargeneem word.

Latere preekbundels vertoon in groeiende mate ' $n$ betrokkenheid met algemene politieke problematiek. Die volgende gedagtelyne kan aangewys word. Politieke ideologieë en ontwikkelinge, ook in Suid-Afrika, word gestel in die perspektief van die Wederkoms (bv. d'Assonville 1977 , Van der Walt T. 1973) ; Afrikaners word gewaarsku teen broedertwis (bv. Buys 1973, p 196) die kerk word gewaarsku teen verpolitisering van kerklike aangeleenthede (bv. Malan 1973, p 229); rassisme word afgewys en "geregtigheid" in volke- en rasseverhoudinge word gevra. Ten opsigte van magsdeling met Indièr- en Kleurlinggemeenskappe waaronder godsdienste soos die Islam en Hindoeisme voorkom was daar preke wat hierdie politieke ontwikkeling veroordeel het met die argument dat die Skrif vermenging met heidene op staatkundige vlak veroordeel.

Tog is dit uit die peiling ten opsigte van gereformeerde prediking opvallend dat predikante, hoewel met 'n duidelike simpatie vir die Afrikaner, huiwerig was om in die prediking 'n politieke model openlik te steun. Daar mag enkele uitsonderings wees, maar in sy geheel sou die gereformeerde prediking nie gedefinieer kan word as "politieke prediking" in die moderne sin van die woord, waar 'n bepaalde staatkundige model as Bybelse voorskrif voorgeskryf word nie.

\subsection{Beoordeling}

Uit die voorafgaande uiteensetting is dit duidelik dat die GKSA in sino- 


\section{In die Skriflig}

dale, ekumeniese en plaaslike verband deur middel van getuienis wel deeglik betrokke was en is by die Suid-Afrikaanse politiek. Tyd, plek en omstandighede het verskillende aksente tot gevolg gehad byvoorbeeld tussen die meerdere vergaderinge onder die blanke gereformeerde gemeenskap en dié onder die swart en kleurlinggemeenskap. Waar "blanke" vergaderinge merendeels besig was met bree beginsels het die "swart" meerdere vergaderings veral in die jongste tyd besig gebly met konkrete gevolge van die Suidu-Afrikaanse sisteem in die lewe van mense. Dit sou egter nie geregverdig wees om hieruit af te lei dat daar tussen "swart" en "wit" gereformeerdes totale teenstrydigheid bestaan in hierdie verband nie.

'n Reduksie van alles wat gesé en besluit is in Gereformeerde kerkverband oor die Suid-Afrikaanse politiek kom te staan op die volgende vyf standpuntinnames:

2.4.1 Die kerk staan nie afsydig teenoor die Suid-Afrikaanse politiek nie. Deur die jare is aspekte van die filosofiese basis, wettesisteem en gevolge daarvan deur verskeie meerdere vergaderings in behandeling geneem. Hoewel in 'n baie mindere mate was ook die prediking binne die GKSA polities betrokke.

2.4.2 Die GKSA het hulle nie prinsipieel verbind aan ' $n$ bepaalde staatkundige model nie. Dit kan geoordeel word dat die 1970-besluit van die Nasionale Sinode die model van apartheid onderskryf het, maar die besluit is in 1985 herroep; dit kan ook geoordeel word dat die klem op verskeidenheid van volke met betrekking tot kerklike organisasie en verhoudinge stimulus gegee het aan die filosofiese basis van apartheid. Baie ander besluite maak egter so ' $n$ konklusie eensydig.

2.4.3 Die verskynsel van rassisme met ander woorde 'n rassemeerderwaardigheids- en minderwaardigheidsteorie en -praktyk word afgewys.

2.4.4 Die huidige en toekomstige model moet ruimte gee vir die uitoefening van basiese menseregte deur al die inwoners van die land.

2.4.5 Wette wat in hulle toepassing lei tot onreg of verdraaiing of vernietiging van Christelike moraal moet gewysig of herroep word. Duidelike voorbeelde hiervan is die kritiek wat uitgespreek is teen die stelsel van trekarbeid, die wet op gemengde huwelike en art. 16 van die Ontugwet.

\section{DIE PAD VORENTOE}

Dit is uit die geskiedenis duidelik dat die GKSA deur middel van die prediking en besluitneming in sinodale en ekumeniese verband gepoog het om Bybelse getuienis te lewer ten opsigte van die Suid-Afrikaanse politiek. Myns insiens was daar altyd 'n versigtige benadering, waarskynlik om trou te bly aan die gereformeerde ekklesiologie. Dit kan met reg gestel word dat die GKSA nie verval het in wat Floor (1975, p 62) op voetspoor van Velema, 'n "subjekverwisseling" noem nie. Hy sê: "So 'n subjekverwisseling vind plaas wanneer ons die Kerk as amptelike instituut wil laat verrig wat die taak is van die gelowiges".

In lyn met die historiese pad wat geloop is op prinsipiële en praktiese vlak; in reaksie op die beginsels en effek van die Politieke Teologie in Suid-Afrika en in antwoord op baie vrae hieroor onder swart en wit gereformeerdes sal die GKSA, myns insiens, vorentoe op dieselfde wyse maar 
nog meer intens by Suid-Afrikaanse politieke ontwikkelinge betrokke raak. 'n Rigtingwyser in hierdie verband het al reeds uit die penne van gereformeerde lidmate verskyn (Van Wyk JH ea. 1983). Hieruit, en uit ontmoeting tussen deputate van die onderskeie Nasionale Sinodes blyk dit dat die volgende sake rakende die Suid-Afrikaanse politiek aan die orde behoort te kom.

\section{1 'n Prinsipiële beoordeling van nuwere politieke ideologiee}

In Suid-Afrika het die Teologie van Bevryding 'n deeglike vastrapplek in die Suid-Afrikaanse kerklike lewe gekry. Verskeie publikasies soos die Kairosdokument en Kairosliturgieè asook ander amptelike kerklike dokumente getuig hiervan. Hierdie Teologie waarmee gereformeerde lidmate, veral in die swart gemeenskap, wel deeglik gekonfronteer word het 'n neo-Marxistiese onderbou (Vorster 1984, p 78 ev) en staan 'n sosialistiese staat in Suid-Afrika voor. Die staatkundige model wat deur die Teologie van Bevryding aangebied word, voldoen myns insiens nie aan die eis van handhawing van die basiese menseregte, soos uitgespreek deur die Nasionale Sinode 1985 op voetspoor van die GES, nie. Vryheid van assosiasie, vrye onderneming en die beskerming van minderhede kom in die gedrang.

Dit blyk dus nodig dat die GKSA 'n duidelike getuienis moet lewer ten opsigte van die Teologie van Bevryding en veral hierdie rigting se politieke model, sy etiek van bevryding en die strategie vir verandering wat voorgestel word.

'n Ander ideologie wat tans lewend is onder Afrikaners en waardeur gelowiges in die kring gekonfronteer word, is wat genoem kan word: Neo-nasionaal-sosialisme. Hierdie rigting is sterk volksgerig en ingestel op die beskerming van Afrikaneridentiteit deur middel van 'n volkstaat. Tans vind die stroming uiting in die AWB wat op die basis van sogenaamde natuurwette die roeping van die kerk onderhewig maak aan die ideale van die volk. Benewens bogenoemde leerstellige dwaling word hier ook basiese menseregte waaronder veral gelykberegtiging en vryheid van diskriminasie wesentlik aangetas. Op leerstellige grond sal die GKSA die rigting moet afwys soos wat reeds deur die Gereformeerde Kerk Lydenburg gedoen is (Geref. Kerk Lydenburg, 1987).

\section{2 'n Prinsipiele beoordeling van teenswoordige politieke strategiee van verandering}

Die Teologie van Bevryding het kerke oor die wêreld ingespan in die uitvoering van rewolusionêre politieke strategiee van verandering. Reeds sedert 1967 het die WRK metodes soos burgerlike ongehoorsaamheid, disinvestering en ander ekonomiese sabotasie en reaksionêre geweld as geregverdigde metodes om politieke verandering teweeg te bring gepropageer (WRK 1967). Sedertdien het hierdie en ander metodes praktyk geword in kerklike geledere - ook in Suid-Afrika (Vorster, 1981 p 18).

Van hierdie strategiee is dit veral die spiraal van geweld, soos deur Camara ( 1969 p 4) gedefinieer, wat ernstige afmetings afgeneem het. Sedert 1984 het geweld 'n feitlik alledaagse verskynsel in swart gemeenskappe in Suid-Afrika geword. En hierdie geweld word onder die titel: 


\section{In die Skriflig}

"geweld wat bevry" geromantiseer en dikwels met indirekte teologiese en kerklike sanksie gepleeg. Vir baie is politieke geweldpleging 'n semireligieuse handeling, solank dit op vryheid gerig is.

Die reg op lewe is deur die Nasionale Sinode (Potchefstroom) as 'n basiese mensereg erken. Op grond hiervan behoort alle geweld prinsipieel veroordeel te word. Dit is ook nodig om, in die huidige omstandighede, weer in te gaan op die houdbaarheid van regverdige opstand soos dit in die 1916-besluit insake die rebellie verwoord is. In hierdie verband moet burgerlike ongehoorsaamheid, ekonomiese sabotasie en dienspligweiering in die fokus kom.

\section{3 'n Prinsipiële beoordeling van wette en hulle gevolge}

Meerdere vergaderings het in die verlede wette en die gevolge daarvan eties beoordeel en met die owerhede daaroor in gesprek getree. Myns insiens behoort die gesprek met owerhede in Suid-Afrika binne die verband van die Algemene Sinode op 'n deurlopende basis gevoer te word. Dit is nodig omaat die inspraak van swart gelowiges, wat op ' $n$ ander wyse deur baie wette geraak word as wit gelowiges, hierin nodig is.

Die kern van alle rassewetgewing in Suid-Afrika is die Bevolkingsregistrasiewet. Hierdie wet is die basis van alle wetlike diskriminasie. Deur die wet word kinders geregistreer as lede van bepaalde bevolkingsgroepe. Teoreties beskou hoef so 'n wet nie probleme op etiese vlak op te lewer nie. Die probleme kom by die implikasies wat so 'n registrasie vir die kind tans inhou. Die dag wanneer 'n swart kind in Suid-Afrika in die huidige omstandighede geregistreer word, word hy die prooi van minderwaardige behandeling ten opsigte van behuising, onderwys, ekonomie, hospitalisasie, politieke inspraak en gesinsverband. Hoewel die toestand verander, is dit juis die laer sosio-ekonomiese peil van die swart gemeenskap wat die groot protes van swart mense uitlok.

Die GKSA behoort, soos in die verlede ten opsigte van ander wette, ook hieroor duidelike getuienis te lewer. Indien dit erns is om basiese menseregte te bevorder, soos die Nasionale Sinode in Potchefstroom in 1985 besluit het, kan 'n prinsipiële beoordeling van alle diskriminerende wette wat voortvloei uit die Bevolkingsregistrasie nie agterweẻ bly nie.

\section{KONKLUSIE}

Bright (1953 p 164) sê ten opsigte van die roeping van die kerk: "The church lives, let it be repeated, in her preaching . . . ." Wanneer dit kom by die roeping ten opsigte van die politiek moet altyd gehou word aan die goue reel: Die kerk lewer getuienis. Hy bied nie politieke bloudrukke nie. Hy is ook nie die lakei van politieke partye en bewegings nie. Hy laat deur getuienis tot owerheid en onderdaan die Woord spreek in die situasie. In alle nederigheid kan gestel word dat die GKSA in plaaslike, sinodale en ekumeniese verband hieraan getrou gebly het - weliswaar met gebreke, leemtes, onduidelikhede en swak formuleringe. Maar die kern van die saak is dat die GKSA 'n roeping ten opsigte van die SuidAfrikaanse politiek vervul het. Getuienis van die Woord in Suid-Afrika tans, dui aan dat die taak nie afgehandel is nie. Daarvoor is daar nog te veel situasies van onreg wat stry teen die "groot gebod" van die koninkryk van God. 


\section{BRONNE WAARNA VERWYS WORD}

Berkhof H. en De Jongh O.J. 1967. Geschiedenis der Kerk. Nijkerk, Callenbach.

Bright J. 1953. The Kingdom of God. New York. The Abingden Press.

Buys P.W. 1973. Broedertwis. (In Booyens M.J. ea. 1973 Evangelie Landswyd. Potchefstroom, Pro Rege p 192-198).

Camara H. 1969. Chrushed by a triple violence. Pro Veritate $8(3)$ p $4 \mathrm{ev}$.

De Gruchy J.W. 1979. The Church Struggle in South Africa. Grand Rapids, Michigan, W.B. Eerdmans.

Coetzee J.V. sj. 'n Ware Volksman (In Aucamp A.L. ea sj. Uit die Ligbron. Potchefstroom, Calvyn Jubileum-Boekefonds p 29-35).

d'Assonville V.E. Sy koms om middernag. Potchefstroom, Marnix;

Fierro A. 1977. The Militant Gospel, An analysis of Contemporary Political Theologies. London, S.C.M. Press.

Floor L. 1974. Die koninkryk van God en die vernuwing van die maatskappy. Potchefstroom. Pro Rege.

Geref. Kerk Lydenburg. Notule van kerkraadsvergadering 3 Februarie 1987.

GKSA 1980. Handelinge van die derde Algemene Sinode van die GKSA. Potchefstroom, Admin. Buro

- - - 1984. Handelinge van die vierde Algemene Sinode van die GKSA. Potchefstroom. Admin. Buro.

---1985 . Handelinge van die 42e Nasionale Sinode in Potchefstroom. Potchefstroom, Admin. Buro.

- - 1987. Memorandum van die Nasionale Sinode Soutpansberg. Ongepubliseer.

Malan C.J. 1973. Ons en ons dode. (In Booyens M.J. ea 1973 Evangelie Landswyd. Potchefstroom, Pro Rege p 234-239).

Van der Walt S.J. 1977. Maranáta, die Here kom. Pretoria (Uitgewer onbekend).

Van der Walt T. 1973. God se more begin vandag - rol op jou moue. Potchefstroom, Pro Rege.

Van Wyk J.H. 1982. Die kerk en 'sy' boodskap aan die wereld van die een en twintigste eeu. In die Skriflig 16(63) p 28-39.

_- - 1983a. Die ouderlinge en toesig oor die lewe. In die Skriflig 17(6) p 24-36

- - ea 1983b. Altyd Reformeer, gesprekke cor godsdiens en politiek. Braamfontein, De Jong.

Vorster J.M. 1981. Die kerk en die kleurvraagstuk vandag. Braamfontein, De Jong (RGN-publikasie nr. 71).

---1981 . Die kruis of die vuis? Kerk en rewolusie in Suid-Afrika. Pretoria, Van Wyk.

- - 1984a. Die neo Marxistiese Politieke Teologie in Suid-Afrika. Potchefstroom, PU vir CHO.

- - 1984b. Die roeping van die kerk in die Suid-Afrikaanse politieke problematiek. Potchefstroom, IRS (194).

WRK 1967. Christians in the technical and social revolutions of our time. World conference on church and society. Geneve, July 12-26 1966. The official report, Geneve WRK. 